\title{
3-N-oxalyl-L-2,3-diaminopropanoic acid, a multifunctional plant metabolite of toxic reputation
}

\author{
Fernand Lambein, ${ }^{\text {a }}$ Yu-Haey Kuo, ${ }^{\text {a }}$ Kuniko Kusama-Eguchi, ${ }^{b}$ and \\ Fumio Ikegamic \\ ${ }^{a}$ Institute Plant Biotechnology for Developing Countries (IPBO), Ghent University, \\ K.L. Ledeganckstraat 35, 9000 Ghent, Belgium \\ ${ }^{b}$ College of Pharmacy, Nihon University, Funabashi 274-8555, Japan \\ ${ }^{c}$ Center for Environment, Health and Field Sciences, Chiba University, 6-2-1 Kashiwanoha, \\ Kashiwa 277-0882, Japan \\ E-mail: fernand.lambein@ugent.be
}

Dedicated to Professor Berhanu M. Abegaz on the occasion of his retirement

\begin{abstract}
3- $N$-oxalyl-L-2,3-diaminopropanoic acid ( $\beta$-ODAP ) is a neuroexcitatory non-protein amino acid identified in grass pea (Lathyrus sativus L.) and in ginseng (Panax spp). Its presence in the drought tolerant grass pea is thought to be responsible for the crippling disease neurolathyrism, while in the longevity promoting ginseng it is named dencichine and praised for its haemostatic properties. Some properties of $\beta$-ODAP are put in perspective.
\end{abstract}

Keywords: Grass pea, Lathyrus sativus, neurolathyrism, $\beta$-ODAP ( $\beta$-N-oxalyl-L- $\alpha, \beta-$ diaminopropionic acid), dencichine, oxidative stress

\section{Introduction}

$\beta$-ODAP (3- $N$-oxalyl-L-2,3-diaminopropanoic acid, or $\beta$-N-oxalyl-L- $\alpha, \beta$-diaminopropionic acid in biological literature) was discovered in the seeds of grass pea (Lathyrus sativus L. family Fabaceae syn. Leguminosae) by two groups in 1964. ${ }^{1,2}$ The discovery of its neuroexcitatory potential led to proposing a role as the neurotoxin responsible for the neurodegenerative disease neurolathyrism. This is an irreversible neurodegeneration of motorneurons resulting in spastic paraparesis of the lower limbs that can vary from mild walking difficulties to bedridden state. This crippling disease with sudden onset affects preferentially the most active young men in destitute remote rural areas and living in a hand-to-mouth economy. Neurolathyrism occurs after prolonged over-consumption of grass pea seed during several months as staple food in an 
unbalanced diet. ${ }^{3}$ In recent history, epidemics have been reported in the Indian subcontinent, China and Ethiopia. The unusual drought tolerance of the grass pea plant has made it a survival food that has saved many human lives during drought triggered famines in Asia and Africa, and allowed the crop to survive agricultural developments since the Neolithicum.

Four decades of plant breeding research to eliminate this non-protein amino acid $\beta$-ODAP from the seed has produced large numbers of "low-toxin" varieties of grass pea but did not yet result in the development of "toxin-free" varieties. A major problem in this endeavour is the high variability of the $\beta$-ODAP biosynthesis. Environmental factors such as drought, zinc deficiency, iron oversupply and the presence of heavy metals in the soil can considerably increase the level of $\beta$-ODAP in the seeds grown in farmers' fields as compared to more optimal experimental fields. ${ }^{4}$ The deficiency of zinc in Bangladesh and the high concentration of iron in Ethiopian soils both have an increasing effect on the $\beta$-ODAP level in the seeds. The presence of cadmium in the soil can increase the $\beta$-ODAP level up to six-fold..$^{5}$ Alternative biotechnological methods for crop improvement were recently reviewed. ${ }^{6}$

Medical and physiological research into the role and the mode of action of $\beta$-ODAP has produced important breakthroughs in the understanding of multiple and intricate effects this glutamate analogue can produce in the cascade of biochemical and physico-chemical reactions governing neuronal signalling. ${ }^{7}$ In the medical literature an incorrect and confusing name for $\beta$ ODAP is often used: BOAA or beta-oxalylamino-alanine. ${ }^{8}$

Botanical and biochemical research has discovered several physiological functions of $\beta$ ODAP in the plant as carrier molecule for zinc-ions, ${ }^{9}$ as scavenger for hydroxyl ions ${ }^{10}$ and as protector of photosynthesis at high light intensity. ${ }^{11}$ The relative tolerance of the plant against biotic and abiotic stress may be related to the presence of $\beta$-ODAP, but convincing proof has not yet been given by the ongoing research. The biosynthetic precursor of $\beta$-ODAP was found to be a UV-light and alkaline-sensitive heterocycle $\beta$-(isoxazolin-5-on-2-yl)-alanine ${ }^{12}$ that is also present in some legume plants not producing $\beta$-ODAP. Only recently it was recognised that $\beta$ ODAP is identical to dencichine, a metabolite of Ginseng roots and seeds. ${ }^{13,14}$ Dencichine is known as a haemostatic and in traditional medicine it is advised against internal haemorrhage. ${ }^{15}$ Studies on this ginseng metabolite have mostly been published in Chinese.

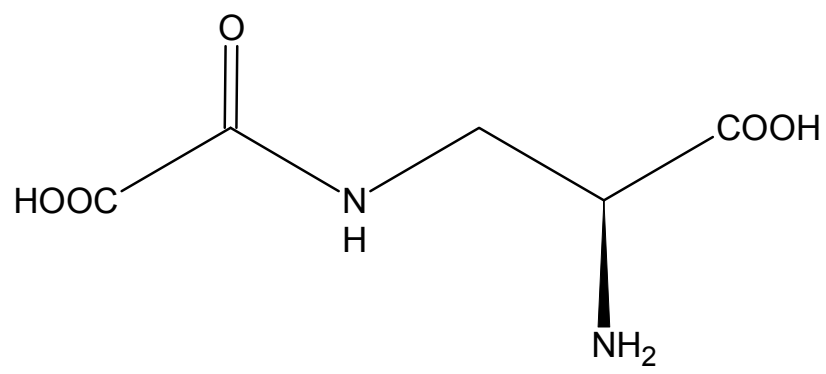

The chemistry of $\beta$-ODAP is remarkable as in aqueous solution it can isomerise spontaneously and form the less toxic $\alpha$-isomer by a zero order reaction affected by $\mathrm{pH}$ and 
temperature and involving a cyclic intermediate. ${ }^{16}$ It also can form chelates with various metal ions. ${ }^{17}$ Fresh plant extracts contain less than $5 \%$ of the $\alpha$-isomer while in aqueous solution an equilibrium of about $60 / 40$ of $\beta$-ODAP/ $\alpha$-ODAP is formed.

Over 30 different chemical, biochemical and physiological activities of this small molecule have been described, however, all those studies did not prevent a major epidemic of neurolathyrism in Ethiopia in 1996-97. ${ }^{18}$ Moreover, sporadic cases continue to occur in some remote drought prone rural areas of Ethiopia. ${ }^{19}$ While the focusing of interdisciplinary research on $\beta$-ODAP to solve the problem of neurolathyrism has diverted attention from other factors in the aetiology of neuroloathyrism, it remains a major factor. Other factors involved are the low amino acid score of the grass pea protein, especially the deficiency of sulphur amino acids methionine and cysteine, ${ }^{20}$ and the role of micronutrients. Micronutrients play a role in the physiology of the plant and can be determining factors in the level of $\beta$-ODAP in the seeds, and also in the maintenance of the redox homeostasis in the human body. Various studies support the idea that oxidative stress may be the crucial factor in neurolathyrism and in other neurodegenerative diseases. Various activities of $\beta$-ODAP and the deficiency of sulphur amino acids also contribute to oxidative stress.

Some chemical, biochemical and pharmacological properties of this small but versatile plant metabolite are reviewed.

\section{及-ODAP Chemistry}

As an analogue of glutamate, $\beta$-ODAP acts on a well defined class of glutamate receptors in the neurones: the AMPA-receptors (alpha-amino-3-hydroxy-5-methyl-4-isoxazole-propanoic acid). It also inhibits the reuptake of glutamate during the neuronal signalling thereby prolonging the excitation. ${ }^{7}$ It can also be recognised by glutamate specific enzymes. The latter property is used to specifically quantitate the beta-isomer of ODAP. ${ }^{21}$ According to Rao, in aqueous solution the molecular modelling of energy minimised structures of glutamate, ODAP and tyrosine indicate that the structure of ODAP is conformationaly cognate more with tyrosine than with glutamate. ${ }^{22}$ This is corroborated by the fact that ODAP does not affect any of the enzymes of glutamate biosynthesis but that the enzyme tyrosine aminotransferase is inhibited by $\beta$-ODAP in a noncompetitive manner. ${ }^{23}$

The most popular method of quantitative analysis is the Rao-method involving alkaline hydrolysis and spectrophotometric measurement of the adduct between 2,3-diaminopropanoic acid that is formed during hydrolysis and $O$-phthaldialdehyde in the presence of mercaptoethanol. With mono-amino acids this reaction yields 1 -alkylthio-2-alkylisoindoles with $\lambda_{\max }=340$, while 2,3-diaminopropanoic acid will yield an imidazo-isoindol derivative 5-(2-hydroxyethylsulfanyl)-2,5-dihydro-3H-imidazo[2,1-a]isoindole-3-carboxylic acid (together with the isomeric -2-carboxilic acid) as shown below with $\lambda_{\max }=426$. Modifications of this method have been compared. ${ }^{24}$ This method does not allow the separate analysis of the isomers but remains useful for screening seed samples. The less quantitative method using reflectance Near Infra Red 
(NIR) methodology is faster and non-destructive and can be routinely used to predict the $\beta$ ODAP level in seed and straw.

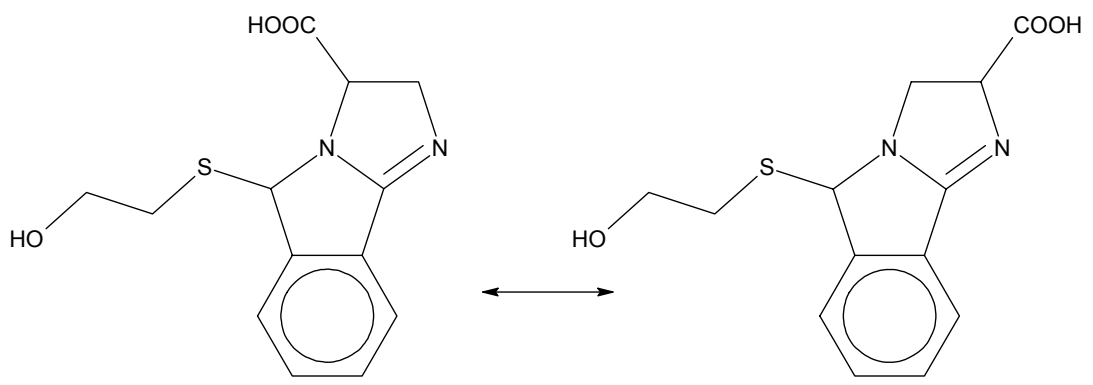

Imidazo-isoindol produced by reaction of 2,3-diaminopropanoic acid with $O$-phthaldialdehyde and mercaptoethanol.

The isomerization of $\beta$-ODAP into the non-toxic alpha isomer (2-N-oxalyl-L-2,3diaminopropanoic acid) has been studied by several groups. The chemical approach by Abegaz and associates led to the proposition that an imidazolidine ring is the unstable intermediate in the isomerization and the result of a water addition. ${ }^{25,26}$ This was further studied by Belay. ${ }^{27}$ This reaction seems to follow a zero-order kinetics in which apparently the solvent water is the catalyst. The analytical approach continues to develop methods to separately quantitate the two isomers. This was achieved by Capillary Zone Electrophoresis (CZE) of the native compounds, ${ }^{28}$ HPLC of derivatives ${ }^{29-31}$ and by on-line bio-sensor analysis exploiting the specific oxidation of $\beta$-ODAP by the enzyme glutamate oxidase. ${ }^{21}$ The nutritional approach speculates on the reduction of toxicity by isomerization during the cooking process. ${ }^{32}$

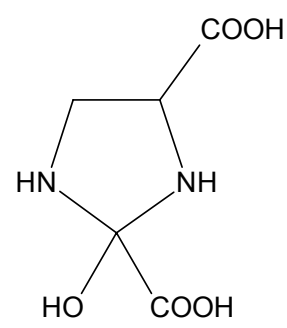

2-hydroxy-imidazolidine-2,4-dicarboxylic acid, the proposed short lived intermediate in the ODAP isomerisation

The spontaneous isomerization of $\beta$-ODAP into $\alpha$-ODAP in water solution reaches an equilibrium that depends on the $\mathrm{pH}$ of the solution. Surprisingly, no study was found on the isomerization and steady state equilibrium in stomach juice of man and of susceptible animal species. Such study and also transport studies through the blood-brain barrier would give a more correct validity to isomerization studies. 
The chelating property of $\beta$-ODAP has been exploited to develop an extraction procedure of $\beta$-ODAP as the copper complex, also the complex formation with zinc and nickel were studied. ${ }^{17,33,34}$ This property might also be involved in the solubilization of zinc and manganese ions from the chick brain into the serum. ${ }^{35}$ Whether this property also affects the redox homeostasis and is involved in the aetiology of neurolathyrism remains an open question.

\section{及-ODAP Biochemistry}

The biosynthesis of $\beta$-ODAP was proposed as an oxalylation of 2,3-diaminopropanoic acid (DAPRO) with oxalyl-coenzyme A. The natural occurrence of DAPRO was never proven and later it was established that this was only a short-lived intermediate between $\beta$-(isoxazolin-5-on2-yl)-alanine (BIA) and $\beta$-ODAP. ${ }^{36}$ BIA is a non-protein amino acid present at high concentration in the seedlings of grass pea, garden pea (Pisum sativum) and lentil (Lens culinaris): up to $2 \%$ of the dry weight of 2-4 days old seedlings with cotyledons removed. ${ }^{36,37}$ Only grass pea has ever been implicated in human toxicity. This biosynthetic pathway was confirmed in various tissues, including cultured cell tissues and developing pod tissues where BIA is under the limit of detection. ${ }^{38,39}$ Labelling experiments with both unstable $\left[{ }^{14} \mathrm{C}\right]$ and stable carbon $\left[{ }^{13} \mathrm{C}\right]$ and nitrogen $\left[{ }^{15} \mathrm{~N}\right]$ isotopes proved that the carbon atoms and the 2 -amino group are derived from the alanyl side chain of BIA, while the 3-amino nitrogen is derived from the isoxazolinone ring. ${ }^{40} \mathrm{~A} \mathrm{H}_{2} \mathrm{O}$-addition to the double bond was proposed as the first step in the opening of the isoxazolinone ring. This water addition also seems to occur under UV-light irradiation $(\lambda=254 \mathrm{~nm})$ in which DAPRO is also released. ${ }^{41}$ These isoxazolinone metabolites are among the most UV-light sensitive natural products having a quantum yield of about 0.5 , meaning that on average one molecule isoxazolinone is broken down per two photons absorbed by the solution.

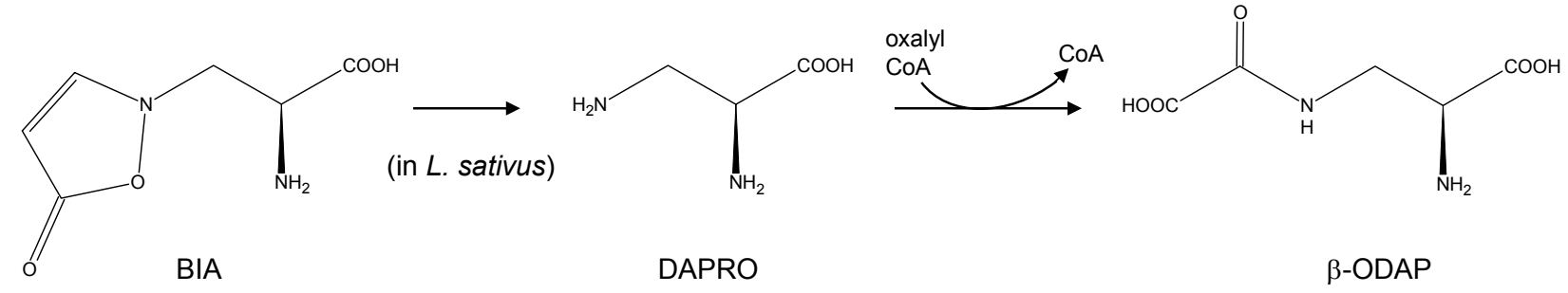

The similarity of the dissolved $\beta$-ODAP molecule to glutamate may play a role in its inhibition of glutamate transport into neuronal astrocyte cells. It also exerts some toxicity against those cells that are the 'power house' producing the energy-rich ATP for the neurons. ${ }^{42}$ The mitochondria, the intracellular power houses of the cell, seem to be specifically affected. ${ }^{43}$ The astrocyte cells normally absorb the glutamate released into the synaptic cleft during neuronal signalling and these glutamate molecules are the normal agents for the excitation at the AMPAreceptors that involves the release of short-lived molecules of nitric oxide (NO). Glutamate absorbed by the astrocytes is metabolised into the less excitatory glutamine. Because of this dual 
effect of $\beta$-ODAP to trigger the AMPA-receptor excitation with the release of the signalling molecule glutamate into the synaptic cleft and to inhibit reuptake of glutamate, the excitation is prolonged and enhanced and the production of NO is much increased and so are the reactive oxygen species produced by this very unstable NO. Specific scavengers for such free radicals protect against the neuronal damage inflicted by $\beta$-ODAP. ${ }^{44}$ The prolonged presence of higher numbers of glutamate molecules that continue to 'excite' the neuronal receptors is the primary effect of $\beta$-ODAP that contributes to oxidative stress.

\section{Pharmacology of $\beta$-ODAP}

There is a high individual and species variation in susceptibility to $\beta$-ODAP and a major problem in the study of neurolathyrism is the absence of a cheap and suitable animal model. Some Bangladeshi farm labourers consume one $\mathrm{kg}$ of grass pea seed per day, which means a daily intake of about $5 \mathrm{~g}$ of $\beta$-ODAP, without ill effect. ${ }^{3}$ Even during epidemic situations when grass pea becomes a survival food and sometimes the only food available, the great majority of the consumers $(>94 \%)$ remain unaffected. This may be explained by the catabolic breakdown of $\beta$ ODAP in humans. ${ }^{45}$ An exceptional situation occurred during World War II in a German labour camp where hard labour was combined with under-nourishment and supply of a diet containing $2 / 3$ grass pea. Over $60 \%$ of the inmates of that camp developed neurolathyrism in various stages of severity. ${ }^{20}$ Inducing symptoms of neurolathyrism in experimental animals required very high doses of $\beta-O D A P{ }^{46}$ or repeated administration at a very early age. ${ }^{47}$

The neuro-physiological effects of $\beta$-ODAP have been studied in detail using various cloned protein elements of neuro-receptors ${ }^{7}$ and cultured cells. Recent experiments suggest that the depletion of the essential sulphur amino acids methionine and cysteine in the medium aggravate the neurotoxicity of $\beta$-ODAP (Kusama-Eguchi, unpublished).

\section{Conclusions}

From a detailed NMR study of $\beta$-ODAP at different $\mathrm{pH}$-values in $\mathrm{D}_{2} \mathrm{O}$, including the calculation of rotamer distribution and intra-molecular hydrogen bonds, De Bruyn and coworkers concluded in 1993 that the limited structural similarity between $\beta$-ODAP and the natural neuroexcitatory amino acid glutamate suggest that this may not be the only reason for its neurotoxicity. ${ }^{48}$ It should be mentioned that grass pea is the only legume that is consumed as a staple food under certain conditions of food insufficiency. The very low amino acid score of grass pea protein, especially the deficiency of the sulphur amino acids cysteine and methionine, ${ }^{20}$ which can be considered as antioxidants, can make the consumer more vulnerable to oxidative stress after a certain time of uninterrupted consumption. Also depletion of the well-known antioxidant vitamin $\mathrm{C}$ seems to sensitize guinea pigs for the neuro-excitation of $\beta$-ODAP. ${ }^{49}$ The chelating properties of $\beta$-ODAP can add to this effect by depleting or translocating micro-nutrients such as zinc, copper and manganese that are essential co-factors of superoxide-dismutase enzymes that are 
important in our defence system against oxidative stress. The neuro-excitation of $\beta$-ODAP can be the extra factor that brings the redox homeostasis out of balance and gives the start for apoptosis of certain sensitised motorneurons. An efficient animal model is still needed to confirm the role of sulphur amino acid deficiency in neurolathyrism and to prove that low $\beta$-ODAP varieties of grass pea are safer and healthier than the traditional varieties.

\section{References}

1. Rao, S. L. N.; Adiga, P. R.; Sarma, P. S. Biochemistry 1964, 3, 432.

2. Murti, V. V. S.; Seshadri, T. R.; Venkitasubramanian, T.A. Phytochemistry 1964, 3, 73.

3. Haque, A.; Hossain, M.; Wouters, G.; Lambein, F. Neuroepidemiology 1996, 15, 83.

4. Campbell, C. G. Grass Pea. Lathyrus sativus L. Promoting the conservation and use of underutilized and neglected crops, 1997; Vol. 18.. Inst. Plant Genetics and Crop plant research, Gatersleben, Germany / International Plant Genetics Resources Inst., Rome, Italy, $91 \mathrm{pp}$.

5. Hussain, M.; Chowdhury, B.; Hoque, R.; Lambein, F. International Conference on Lathyrus and lathyrism, a decade of progress. Addis Ababa, Ethiopia, Nov 27-29, 1995, Abstract p 57-60.

6. Vaz Patto, M. C.; Skiba, B.; Pang, E. C. K.; Ochatt, S. J.; Lambein, F.; Rubiales, D. Euphytica 2006, 147, 133.

7. Kusama, T.; Kusama-Eguchi, K.; Ikegami, F.; Yamamoto, A.; Kuo, Y. H.; Lambein, F.; Watanabe, K. Res. Comm. Pharmacol. Toxicol. 2000, 5, 37.

8. Weber, K. T. Cardiovasc. Res. 1998, 37, 551.

9. Lambein, F.; Haque, R.; Khan, J. K.; Kebede, N.; Kuo, Y. H. Toxicon 1994, 32, 461.

10. Zhou, G. K.; Kong, Y. Z.; Cui, K. R.; Li, Z. X.; Wang, Y. F. Phytochemistry 2001, 58, 759.

11. Zhang, J.; Xing, G. M.; Yan, Z. Y.; Li, Z. X. Russ. J. Plant Physiol. 2003, 50, 618.

12. Lambein, F.; Ongena, G.; Kuo, Y. H. Phytochemistry 1990, 29, 3793.

13. Dong, T. T. X.; Cui, X. M.; Song, Z. H.; Zhao, K. J.; Ji, Z. N.; Lo, C. K.; Tsim, K. W. K. J. Agricult. Food Chem 2003, 51, 4617.

14. Kuo, Y. H.; Ikegami, F.; Lambein, F. Phytochemistry 2003, 62, 1087.

15. Zhang, G. D.; Cui, J. F.; Li, H. Y. Chin. J. Pharm. Anal. 1990, 10, 209.

16. Belay, A.; Moges, G.; Solomon, T.; Johansson, G. Phytochemistry 1997, 45, 219.

17. Nunn, P. B.; Obrien, P.; Pettit, L.; Pyburn, S. I. J. Inorg. Biochem. 1989, 37, 175.

18. Getahun, H.; Mekonnen, A.; Teklehaimanot, R.; Lambein, F. Lancet 1999, 354, 306.

19. TekleHaimanot, R.; Feleke, A.; Lambein, F. Ethiop. J. Health Devel. 2005, 19, 230.

20. Lambein, F.; Ngudi, D. D.; Kuo, Y. H. Lathyrus Lathyrism Newsl. 2001, 2, 5.

21. Moges, G.; Wodajo, N.; Gorton, L.; Yirgalem Yigzaw, Y.; Kalcher, K.; Belay, A.; Akalu, G.; Nair, B. M.; Solomon, T. Pure Appl. Chem. 2004, 76, 765.

22. Rao S. L. N. Lathyrus Lathyrism Newslett. 2001, 2, 2. (http://go.to/lathyrus)

23. Vardhan, K. S.; Rudra, M. P. P.; Rao, S. L. N. J Neurochem. 1997, 68, 2477. 
24. Hussain, M.; Chowdhury B.; Haque, R.; Wouters, G.; Campbell, C. G. Phytochem. Anal. 1994, $5,247$.

25. Abegaz, B. M.; Nunn, P. B.; De Bruyn, A.; Lambein, F. Phytochemistry 1993, 33, 1993, 1121.

26. De Bruyn, A.; Becu, C.; Lambein, F.; Kebede, N.; Abegaz, B. M.; Nunn. P. B. Phytochemistry 1994, 36, 85 .

27. Belay, A.; Moges, G.; Solomon, T.; Johansson, G. Phytochemistry 1997, 45, 219.

28. Arentoftt, A. M. K.; Greirson, B. N. J. Agric. Food Chem. 1995, 43, 942.

29. Khan, J. K.; Kebede, N.; Kuo, Y. H.; Lambein, F.; De Bruyn, A. Anal. Biochem. 1993, 208, 237.

30. Khan, J.K.; Kuo Y.-H.; Kebede, N.; Lambein, F. J. Chromatogr. A 1994, 687, 113.

31. Yan, Z.; Wang, Y.; Jiao, C.; Li, F.; Liang, Y.; Li, Z. Chromatographia 2005, 61, 231.

32. Padmajaprasad, V.; Kaladhar, M.; Bhat, R. V. Food Chem. 1997, 59, 77.

33. Davies, A. J.; Nunn, P. B.; O’Brien, P.; Pettit, L. D.; Wang, G. F. J. Inorg. Biochem. 1990, 39, 209.

34. Malisza, K. L.; Briggs, C. J.; Hasinoff, B. B. J. Inorg. Biochem. 1997, 65, 251.

35. Lambein, F.; Kuo, Y.-H.; Chowdhury, B.; Ikegami, F.; Briggs, C. Symposium "Molecular Mechanisms of Toxicity" 1997, Department of Biochemistry, Osmania University, Hyderabad, India. $\mathrm{p} 1$.

36. Kuo, Y.-H.; Ikegami, F.; Lambein, F. Phytochemistry 1998, 49, 43.

37. Rozan, P.; Kuo, Y. H.; Lambein, F. Phytochemistry 2001, 58, 281.

38. Kuo, Y. H.; Lambein, F. Phytochemistry 1991, 30, 3241.

39. Kuo, Y. H.; Khan, J. K.; Lambein, F. Phytochemistry 1994, 35, 911.

40. Kuo, Y. H.; Lambein, F.; Mellor, L. C.; Adlington, R. M.; Baldwin, J. E. Phytochemistry 1995, $37,713$.

41. De Bruyn, A.; Verhegge, G.; Lambein, F. Planta Medica 1992, 58, 159.

42. Bridges, R. J.; Hatalski, C.; Shim, S. N.; Nunn, P. B. Brain Res. 1991, 561, 262.

43. Ravindranath, V. Neurochem. Internat. 2002, 40, 505.

44. Willis, C. L.; Meldrum, B. S.; Nunn, P. B.; Anderton, B. H.; Leigh, P. N. Neurosc. Lett. 1994, 182, 159.

45. Rudra, M. P. P.; Singh, M. R.; Junaid, M. A.; Jyothi, P.; Rao, S. L. N. Clinical Biochem. 2004, 37, 318.

46. Spencer, P. S.; Ludolph, A.; Dwivedi, M. P.; Roy, D. N., Hugon, J.; Schaumberg, H. H. Lancet ii 1986, 1066.

47. Kusama-Eguchi, K.; Ikegami, F.; Kusama, T.; Suda, A.; Ogawa, Y.; Igarashi, K.; Watanabe, K. Amino Acids 2005, 28, 139.

48. De Bruyn, A.; Van Haver, D.; Lambein, F.; Abegaz, B. M. Natural Toxins 1993, 1, 328.

49. Amba, A.; Kumar, M.; Upreti, R. K.; Khanna, S. K.; Das, M. Biomed. Environm. Sc. 2002, 15,315 . 